\title{
Detection of Interannual Vegetation Responses to Climatic Variability Using AVIRIS Data in a Coastal Savanna in California
}

\author{
Monica Garcia and Susan L. Ustin, Member, IEEE
}

\begin{abstract}
Ecosystem responses to interannual weather variability are large and superimposed over any long-term directional climatic responses making it difficult to assign causal relationships to vegetation change. Better understanding of ecosystem responses to interannual climatic variability is crucial to predicting long-term functioning and stability. Hyperspectral data have the potential to detect ecosystem responses that are undetected by broadband sensors and can be used to scale to coarser resolution global mapping sensors, e.g., advanced very high resolution radiometer (AVHRR) and MODIS. This research focused on detecting vegetation responses to interannual climate using the airborne visible-infrared imaging spectrometer (AVIRIS) data over a natural savanna in the Central Coast Range in California. Results of linear spectral mixture analysis and assessment of the model errors were compared for two AVIRIS images acquired in spring of a dry and a wet year. The results show that mean unmixed fractions for these vegetation types were not significantly different between years due to the high spatial variability within the landscape. However, significant community differences were found between years on a pixel basis, underlying the importance of site-specific analysis. Multitemporal hyperspectral coverage is necessary to understand vegetation dynamics.
\end{abstract}

Index Terms-Airborne visible-infrared imaging spectrometer (AVIRIS), endmembers, linear spectral unmixing, mediterranean grassland, rainfall variability, savanna.

\section{INTRODUCTION}

$\mathbf{E}$ COSYSTEM responses to interannual weather variability are large, especially in the case of semiarid areas where water is the main limiting resource. A better understanding of these responses is crucial to predicting long-term ecosystem functioning and stability, and for improving watershed and rangeland management [1], [2]. However, detecting changes in net primary production (NPP) and establishing relationships to climate variation is complicated. In principle, NPP is limited by climate and biogeochemical cycles, but is also modulated by feedbacks from canopy development and differences in source-sink relationships across the landscape [3], [4]. Additionally, interacting processes occur at multiple rates and spatial scales [5]. To study interannual changes, both long-term climatic responses and short-term seasonal responses must

\footnotetext{
Manuscript received August 31, 2000; revised February 4, 2001. This work was supported in part by Foundation Barrie de la Maza, Spain, and NASA EOS Program Grant NAS5-31359.

The authors are with the Center for Spatial Technologies and Remote Sensing (CSTARS), Department of Land, Air and Water Resources, University of California, Davis, CA 95616-8671 USA (e-mail: slustin@ucdavis.edu).

Publisher Item Identifier S 0196-2892(01)05487-0.
}

be taken into consideration [6]. Changes in NPP are explicit only at a given combination of spatial and temporal scales [1], and the choice of appropriate temporal and spatial sampling is critical [7].

In Mediterranean ecosystems, most of the interannual variation in NPP relates to rainfall patterns [8], but it is also highly dependent on species ecophysiology and site microenvironment. Within a plant community, both phenology and NPP are a function of spatial and temporal availability of water. High variability in winter rainfall produces variable intensities of summer drought [8]-[10]. Climate uncertainty has favored flexibility in response to water availability that is different between communities and between species within communities. Therefore, to monitor NPP at a landscape scale, it is necessary to have sufficient spatial resolution and coverage to separate community types. Nonetheless, there remain many uncertainties about how variability in the structure and chemistry of plant communities modifies reflectance and thus influences the interpretation of NPP [11]-[13], especially for vegetation types like evergreens or plants under stress, where there is no functional convergence with structure [11], [14], [15].

Vegetation dynamics, and carbon fluxes at coarse scales have been estimated using the normalized difference vegetation index (NDVI) derived from advanced very high resolution radiometer (AVHRR) or multispectral scanners (MSS) because of availability of multitemporal sampling. [16]-[19]. However, they miss important changes in vegetation, especially in semiarid areas, where background and litter greatly affect spectral signatures [2]. Hyperspectral sensors like the airborne visible-infrared imaging spectrometer (AVIRIS) capture more spectral information because they have a large number of contiguous narrow spectral bands, often of $10 \mathrm{~nm}$ width or narrower, from instruments with a high SNR [20]. Also, hyperspectral sensors have high spatial resolution which allows more precise ecological analysis.

At present, the use of hyperspectral sensors in change detection studies have been limited due to inadequate multitemporal coverage [21], [22]. Nonetheless, these change studies show promise and benefit from improved calibration methods that isolate atmospheric and instrument artifacts from actual growth changes within plant communities [23]. Change detection studies between years have been successful under conditions where drastic agents such as wildfire or land uses were involved. However, detecting vegetation changes between years due solely to climatic variability is a challenge because community responses are subtle. To achieve good results, it is necessary 
to minimize all sources of reflectance variability other than vegetation, such as misregistration, atmospheric calibration, illumination, detectors, sun angles, and plant phenological differences [24], [25].

The purpose of this research was to identify interannual-term responses in NPP due to climate variability, observed during the period of peak spring growth, using hyperspectral data from AVIRIS collected over a natural savanna in California. Hyperspectral data have potential to improve NPP estimates by improving the accuracy of leaf area index measurements, better estimates of turnover of foliage and woody stems, and estimates of plant stresses that reduce GPP below maximum values. At this time, phenological differences between plant communities are minimal and differentatiation is least distinct. The study compares a strong wet El Niño year and a dry (below normal precipitation) year at the end of a weak cold El Niño Southern Oscillation (ENSO) event (La Niña) (http://www.cpc.ncep.noaa.gov). The years differ in the magnitude and distribution of rainfall over the year. The study site is Stanford University's Jasper Ridge Biological Preserve (JRBP), Palo Alto, CA, in the central California Coast Range. There is a long history of ecological and remote sensing research at this site with higher temporal coverage of AVIRIS imagery than for any other place [22]. The JRBP has significant biodiversity over a relatively small extent (482 ha). Hyperspectral data has been shown to correlate with vegetation structure at JRBP and in other semi-arid areas [26]-[28] and is assumed to be a measure of net ecosystem production (NEP) occurring over the landscape [29]-[32]. Model approaches have used vegetation indices and spectral mixture analysis (SMA).

In late spring, all vegetation types are at or near the peak of their annual productivity and spectral differences between vegetation types are less than other seasons when deciduous trees and grasses are dormant. SMA [34] has been one of the most successful techniques to quantify vegetation abundance and show seasonal trends consistent with field data [22], [28], [30], [31]. The types of canopy changes that can be detected in the spring are related to NPP and the abundance of plant litter and stems, i.e., the nonphotosynthetic components of plant canopies. Because measurements of green foliage or biomass in late spring are at or near the peak of the phenological cycle they should be correlated with NPP. Spring measurements have greater functional convergence between biomass and carbon fixation for all vegetation types including evergreen trees [35], therefore, linking structure and function becomes more direct than at other times of the year.

\section{DESCRIPTION OF DATA}

\section{A. JRBP Study Site}

JRBP is located in the eastern foothills of the Santa Cruz mountains, at 37 24'N latitude and 122 13'30'W longitude. A vegetation map was available, which was produced from aerial photographs and field observations by Chiarello (1989) [36]. The 500 ha of JRBP are composed of five main vegetation types: evergreen forest, deciduous forest, chaparral shrublands, herbaceous perennial wetlands, and annual grasslands. Topography and soil patterns create relatively high spatial heterogeneity (http://jasper1.stanford.edu) [22], [35]. The serpentine soils (15 ha) support endemic grasses and forbs tolerant to low calcium soils that have lower growth potential than grasses growing on the greenstone Franciscan soil. The greenstone grasses are mainly introduced European annuals which support less biodiversity than serpentine grasslands. The mixed evergreen forest is composed of 150 ha of California bay, live oak, madrone, and some stands of redwood and Douglas fir. There are 15 ha of blue oak savanna, which is considered winter-deciduous except in extremely dry years when it is drought-deciduous [37], and 140 ha of chaparral communities composed of several types of shrubs. The remaining 150 ha include the lake, wetland, and riparian corridors (http://jasper1.stanford.edu).

\section{B. AVIRIS Data}

Two AVIRIS images of JRBP were acquired on May 3, 1996, and April 29, 1998, following northeast and northwest flight lines, respectively (Figs. 1 and 2). Datasets had a nominal ground resolution of $20 \mathrm{~m}$, spectral resolution of $10 \mathrm{~nm}$, and 16-bit radiometric resolution. The choice of these images was driven by the significant difference in rainfall between the two years and the similar dates of the images. The 1995/1996 and 1997/1998 spring climates were within a weak "La Niña" and a strong "El Niño" event, respectively, which in California are expressed as dry and wet years. In the 1995/1996 season, total rainfall was $794 \mathrm{~mm}$ and in the $1997 / 1998$ season it was 1333 mm.

Percent surface reflectance was calculated using a modified MODTRAN model [23], [38] using standard atmospheric conditions. To ensure that reflectance levels were equivalent, the images were radiometrically aligned to an April 1997 Jasper Ridge image by regression using pseudo-invariant features (PIF) corresponding to road pixels. The 1997 image was aligned with field spectra obtained that year (D. Roberts, personal communication). It is remarkable that SNR levels improved in 1998 by almost a factor of two in most spectral regions due to improvements in the AVIRIS spectrometers. Thus, in 1998, the highest $\mathrm{S} / \mathrm{N}$ levels calculated for a $50 \%$ reflectance target at sea level and $23.5^{\circ}$ zenith angle corresponds in the A spectrometer $(0.7$ $\mu \mathrm{m})$ to levels of 1000:1, and the lowest were measured in the SWIR region $(2.2 \mu \mathrm{m})$ with maximum levels of 400:1 [23].

\section{Georeferencing}

A digital orthophoto quad (DOQ) from United States Geological Survey (USGS) corresponding to Palo Alto South West (PASW) quadrangle in UTM coordinates with $1 \mathrm{~m}$ pixel resolution was used to georeference the 1998 scene using 43 points. The root mean square error (RMSE) using a first-order polynomial warp was less than 0.05 pixels or $1 \mathrm{~m}$. The study area of 500 ha is without large topographic gradients therefore, using a polynomial function was appropriate. The 1996 image was coregistered to the 1998 image to ensure that registration for change detection was accurate. The error was less than 0.4 pixels or 8 $\mathrm{m}$, also using a first-order degree polynomial and 44 points. In order to avoid spectral resampling after warping, the derived images were warped instead of the original spectral bands. However, in some areas of the scene, it was necessary to use the vege- 


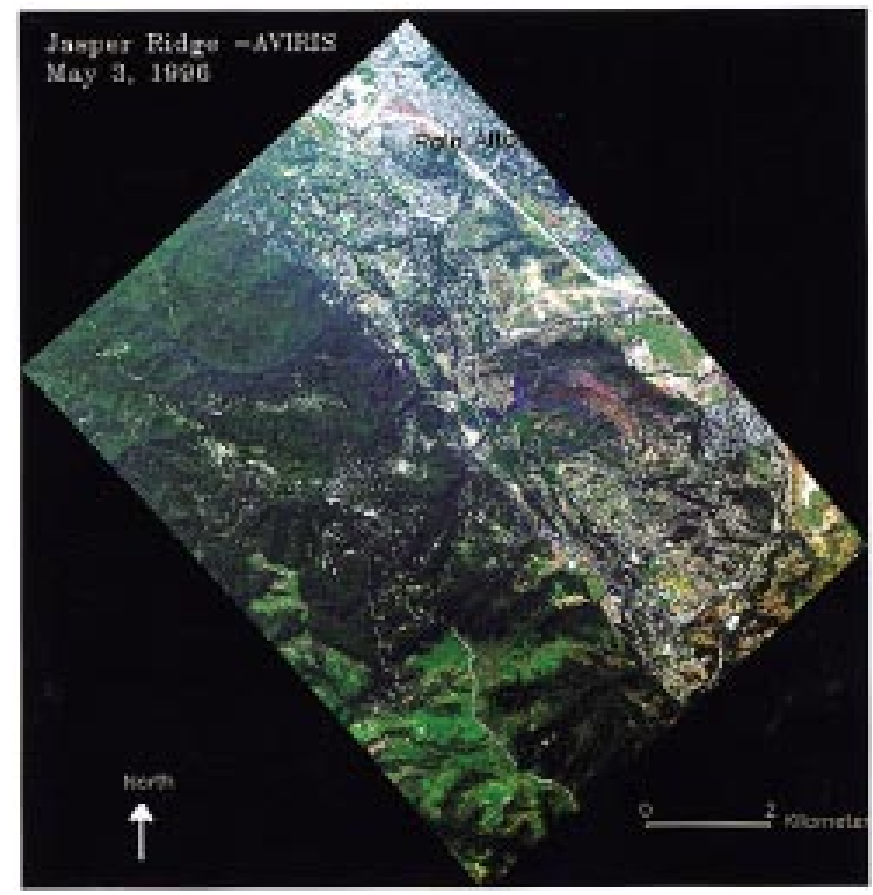

Fig. 1. True color composite in RGB from May, 3 1996, AVIRIS reflectance image of Jasper Ridge Biological Preserve, delineated by white line.

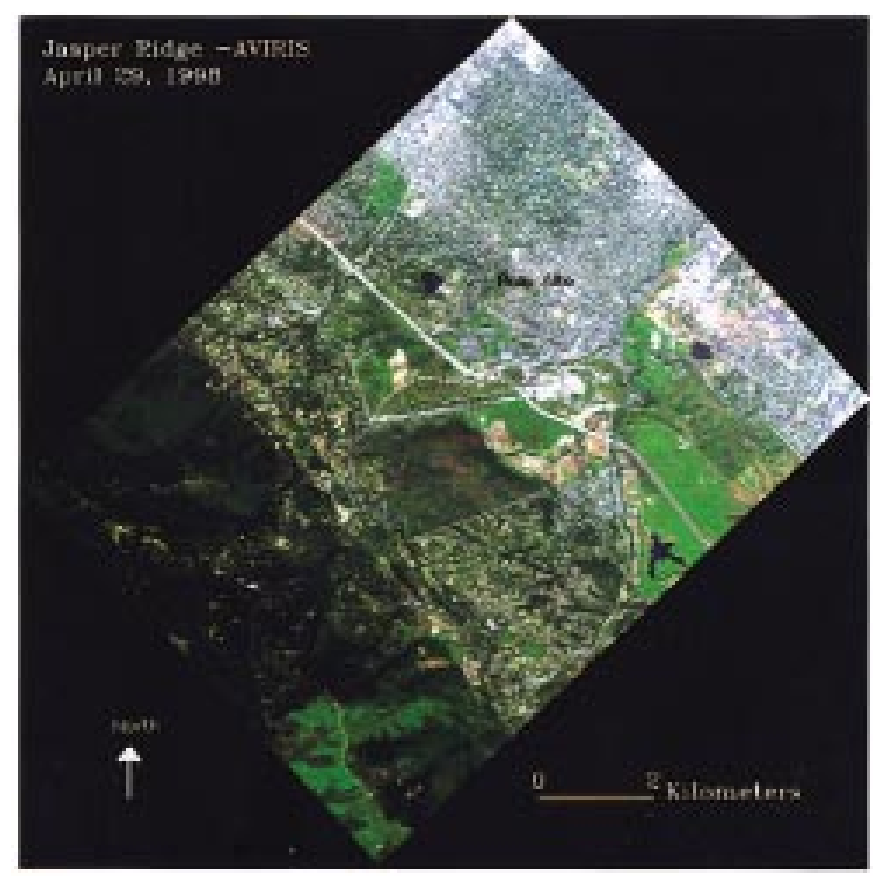

Fig. 2. True color composite in RGB from April 29, 1998, AVIRIS reflectance image in Jasper Ridge Biological Preserve, delineated white line.

tation map and apply a different endmember set and in this case, all spectral bands were warped.

\section{METHODS}

The method used to detect and quantify changes between years was linear SMA [34]. The advantages of using linear spectral unmixing from hyperspectral data apply especially to semi-arid areas where green cover is low and soil and litter greatly affect pixel reflectance [2], [11], [28]. In these, the problem of nonlinear mixing is secondary as the thick leaves of xerophytic vegetation and sparse canopy cover decrease multiple scattering of photons [39]. In fact, linear SMA has been widely used for hyperspectral and TM data at Jasper Ridge and other semi-arid sites with even lower primary productivity. In those studies, characterization and quantification of vegetation structure and functioning using unmixing was consistent with the ecological trends and field measurements [2], [14], [24], [39], [42]. The SMA equations are solved through linear least squares fitting. The maximum RMSE between the observed and the predicted image reflectance is minimized. Negative fractions are an indication that the endmember selection was not appropriate. RMSE is a measure of the amount of spectral reflectance not accounted by the model, and therefore can be used to estimate the goodness of fit in the model, which should be at a level similar to instrument noise [2].

\section{A. Endmember Selection}

Finding appropriate endmembers is a critical step and spectra of various plant canopies, litter, shadow, and soil were used [15], [27], [41], [43]. A unique solution may not be best, particularly for extending a model to a wider region, and a subjective decision must be made based on the purpose of the research and the outputs of the SMA process. High RMSE or high band residuals $\left(e_{\mathbf{i}}\right)$ and negative or unrealistic fractions indicate a bad fit of the model and reveals inappropriate endmember selections [41]. Basically, there are two ways to select endmembers: reference endmembers in spectral libraries come from field data that are used to represent landscape components, and image endmembers, which represent "pure" pixels in the image. One of the main difficulties in the first method is that the library might not match the phenology at the time of the image, or that there is miscalibration between field spectra and image spectra, or because it is complicated to decide which endmembers are the most "representative." In contrast, image endmembers may closely match pixel spectra in the image but may be mixtures themselves and make identification of the materials uncertain. Both methods share calibration requirements, which is essential for atmospheric retrieval and extension of the methods to other sites [24], [35], [44].

A hybrid method combining automatic and supervised endmember selections was performed on the 1998 image following methodology proposed by Boardman in 1993 [44]. Water vapor bands and noisy bands were removed to reduce noise and data dimensionality. The minimum noise fraction (MNF) algorithm was applied to the reflectance image and the pixel purity index (PPI), as implemented in the Environmental Visualizing Images software package (RSI, Boulder, CO) was calculated in regions of interest at Jasper Ridge (selected following decreasing variance) within MNF dimensional space. The minimum noise fraction transform is essentially two cascaded principal components transformations that first computes the estimated noise covariance matrix to decorrelate and rescale the noise in the data and then performs a standard principal components transform of the noise-whitened data. PPI is a search routine for the most spectrally pure (extreme) pixels (i.e., candidate endmembers) in the image. The pixels with the highest PPI values were selected, as 
they are linearly independent in most dimensions. The same procedure was followed on the 1996 image. Endmembers used in the SMA came from the 1998 image as vegetation was greener and because signal-to-noise levels were improved with respect to 1996.

\section{B. Error Analysis}

Accurate change detection requires minimizing other sources of reflectance variation between dates [24], [25]. One source of error is misregistration between images, but differences in phenological stage, sensor angle, zenith angle, and solar azimuth, clouds, and atmospheric effects must be accounted for. Illumination differences between years were minimal as image acquisition was only one week apart. Comparison of biweekly NDVI composites of the study area from AVHRR between 1994 and 1998 show that peak greenness occurs at these dates, ensuring comparability of phenological stage (Fig. 3).

RMSE for the JRBP area was used as a criterion for goodness-of-fit for endmember selection. RMSE is defined for each pixel as

$$
\operatorname{RMSE}=\sqrt{\sum_{\lambda=1}^{n}\left(R_{o}(\lambda)-R_{u}(\lambda)\right)^{2}}
$$

where

$$
\begin{array}{ll}
R_{o}(\lambda) & \text { pixel reflectance; } \\
R_{u}(\lambda) & \text { modeled pixel spectral reflectance; } \\
n & \text { number of bands. }
\end{array}
$$

Analysis of residuals between observed AVIRIS reflectance and modeled SMA reflectance corresponding to each spectral band has been used to identify materials poorly fit by the reference endmembers [21]. In this study, an analysis of the specific contribution from each spectral band to total error and spatial variation in the error was used to assess model results. Residuals were calculated per band and per pixel. Additional error sources stem from the spectral and radiometric calibration procedure, in-flight system changes, solar irradiance model errors, and inaccuracy in parameter estimation [46]. In our case, the threshold level chosen to assess the goodness-of-fit in the model was 3\% of maximum reflectance in each band. Because error is correlated with magnitude of reflectance, the areal extent for which the maximum error was calculated was restricted to the JRBP where the preexisting vegetation map could be used to mask the results and analyze error(s) for each vegetation type.

Interpreting the cause(s) of high residuals is not easy. A combination of factors decreases the fitness of the model. One type includes spectral features not accounted for by the selected endmembers. Thus, heterogeneous biochemical and structural characteristics or gradual changes in soil and vegetation properties contribute to this error. Another source of error is caused by nonlinear effects associated with multiple scattering of photons, especially in the NIR and SWIR bands. Vegetation structure and leaf optical properties or high background reflectance contribute to nonlinear scattering. Finally, systematic errors from illumination and atmospheric conditions, sensor effects, and calibration procedures increase error in the model [11], [22]. Effects of nonlinear spectral mixing are most evident in the NIR as little

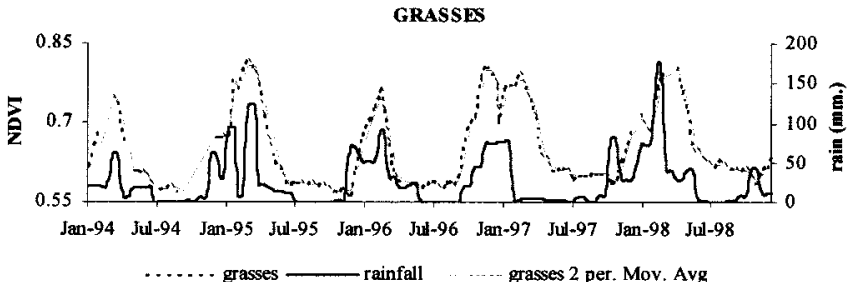

EVERGREN
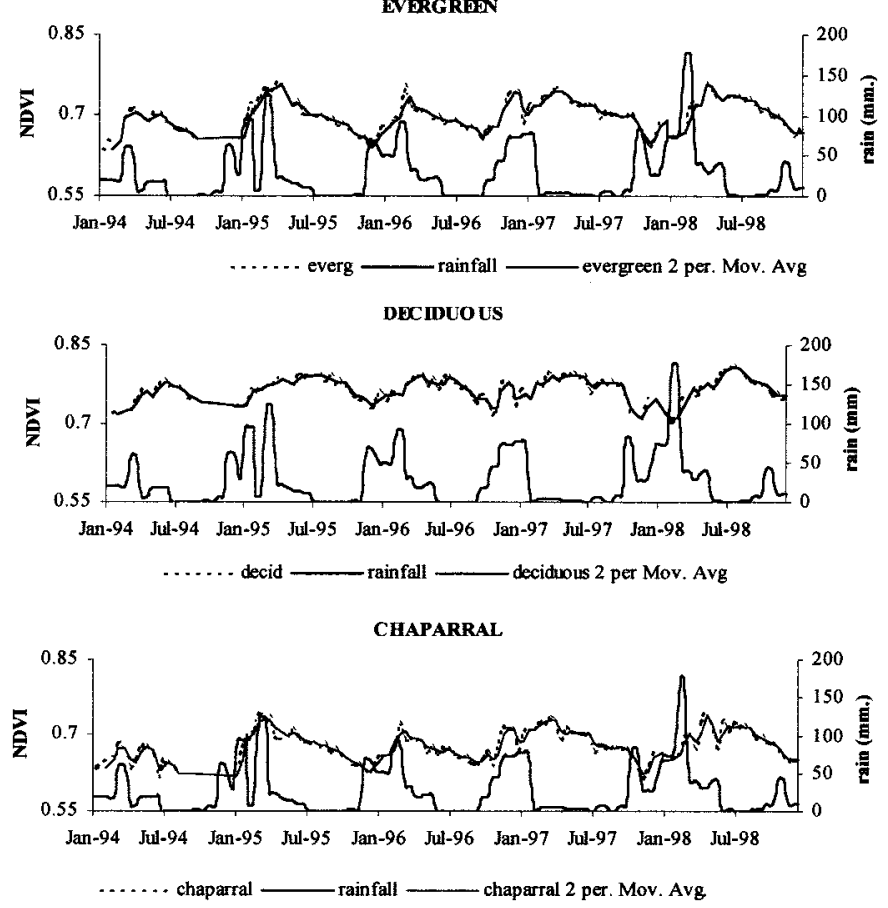

Fig. 3. Temporal NDVI series derived from bimonthly composite AVHRR data. The mean NDVI was calculated for the Santa Cruz Mountains extent between 1994 and 1998.

leaf absorption occurs at these wavelengths. The degree of nonlinearity caused by multiple scattering of photons depends on leaf transmittance, which is lower in xerophytic vegetation like chaparral and evergreen conifers and higher in grasses and some deciduous shrubs and trees [21], [22], [27]. Nonlinear mixing increases with canopy cover and with background reflectance for brighter soils and standing litter [11]-[13], [41].

\section{RESULTS AND DISCUSSION}

Linear SMA using three endmembers, soil (Franciscan greenstone), green vegetation (evergreen forest), and shade was applied to 1996 and 1998 images. Residual analysis of each spectral band showed high error for areas of JRBP that were composed of dry grass and litter, justifying the addition of a dry grass endmember. Based on this analysis, a new set of four endmembers: soil, green vegetation, shade, and dry grass, was applied to the grassland areas where RMSE was high. The grassland boundaries were defined in the image using the Greenstone and Serpentine vegetation boundaries in the Jasper Ridge Vegetation Map [36].

\section{A. Endmember Selection}

Automatic endmember selection was determined using the MNF bands. MNF transformed spectra were related to spec- 


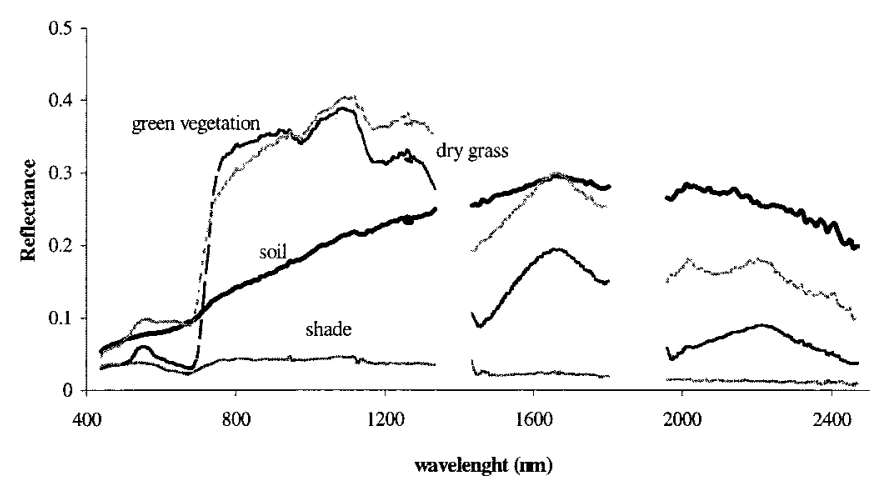

Fig. 4. Set of endmembers used for unmixing. Green vegetation and dry grass were selected automatically based on PPI, soil by visual inspection, and shade by minimum albedo levels in the image, corresponding to a lake.

tral properties of different vegetation types, dry grass, and soils. Pixels with the highest PPI in MNF space corresponded to soil, vegetation and water spectra. However, because vegetation at Jasper Ridge is patchy and spring grasses grow almost everywhere, no pure soil pixels were found. Instead, soil from a bare field east of JRBP was used after evaluating different soil spectra and unmixing results. The water endmember used to model the shade component was also from a lake outside JRBP. It was chosen because its albedo was the lowest in the entire scene. (Fig. 4).

Linear SMA was performed after applying several combinations and numbers of endmembers. Selection criteria were realistic fraction distributions (i.e., between 0-100\%) and low RMSE. The best fit endmembers for JRBP corresponded to a combination of evergreen vegetation, soil and shade spectra. Adding an additional endmember, plant litter, did not improve the general fit, because 1) at this time of the year, all vegetation except grasses are green and have little canopy litter, and 2) the litter endmember was confounded with the soil endmember. Fig. 5 shows a red, green, blue (RGB) composite of soil, green vegetation, and shade fractions. Specific combinations of endmember fractions (as observed by the color variation) are consistent for specific vegetation types. These results demonstrate vegetation patterns described for JRBP and for other sites [22], [39].

\section{B. Error Analysis}

Mean RMSE at Jasper Ridge, for SMA with three endmembers, was $0.84 \%$ in 1996 and $0.64 \%$ in 1998 , with standard deviations of $0.43 \%$ and $0.21 \%$, respectively. Lower error occurred in 1998 compared to 1996, which is related to improvements in the A and D spectrometers in 1998. However, spatial distribution of RMSE shows speckled areas with high RMSE in the partially senesced grasslands. In addition, green canopy cover is lower, and soil background effects are higher in this type compared to other vegetation types.

The per band residuals analyzed over the entire image were in the worst case, less than $4 \%$ reflectance (Fig. 6). However, the spatial and spectral analysis of residuals shows that the error contribution of each band is different and varies depending on vegetation type. It also highlights spectral differences between years. Fig. 6 shows that almost all vegetation types fit within error threshold levels, except the grasslands. Both serpentine and greenstone grasslands had high residuals in the visible, NIR, and SWIR bands in 1996 and in 1998. When residuals are high and positive in the visible range, the model overestimates vegetation or underestimates soil, as vegetation reflectance is very low in this range. In the same way, high negative residuals in the NIR reflect an overestimation of vegetation as observed reflectance is less than modeled and vegetation reflectance dominates in the NIR wavelengths. In senescent plants, these errors can be related to low chlorophyll concentrations and high positive residuals in the red spectral region, low leaf water content and high positive residuals in the SWIR, and lower NIR-plateau reflectance, and high negative residuals in the NIR. As a consequence, senescent or stressed vegetation has a red edge that is shifted toward the blue region, decreasing the fitness of the selected green endmember. All of these RMS characteristics are associated with JRBP areas of senescent grasses and plant litter. This effect on RMS band residuals is stronger in 1996 than in 1998, corresponding to the more droughty condition in 1996. The error attributable to extrapolation of endmembers from 1998 to 1996 does not produce changes in residuals in other vegetation types, such as evergreen forest and chaparral, which are on the same order in both years. The high negative residuals in SWIR bands in 1996 may also be responding to increased cellulose and lignin absorptions due to the presence of more canopy litter.

The effect of enhanced multiple scattering with greater canopy cover is observed in Fig. 7 for deciduous forest pixels that have high leaf transmittance. In this vegetation type, soil fractions are low and SMA adjustments come from changes in vegetation and shade fractions. The observed spectra had the same spectral features in both years but different albedo, which is related to greater canopy cover in the wetter 1998 .

In Fig. 6, residuals are shown for grasslands from different soil backgrounds: serpentine and greenstone soils. When green canopy cover is high, reflectance residuals are low. However, with lower canopy cover, spikes in the red-edge region are large for greenstone and serpentine grasslands, suggesting that the reflectance model for either plant litter or soil could be improved. In the NIR, negative residuals indicate overestimation of vegetation abundance. At this time in spring, serpentine grasslands are drier than greenstone grasslands, which explains their lower negative residuals in the NIR. However, in the red-edge wavelength region, residuals are higher for greenstone grasses where the background soil is brighter, which enhances nonlinear scattering more than the darker serpentine soils. This suggests that the effect of plant litter is greatest in the NIR and the effect of the soil background is more important near the red-edge.

Standing litter increases reflectance at $680 \mathrm{~nm}$, reduces NIR reflectance, increases the slope of NIR between 800 and 1000 $\mathrm{nm}$, and increases SWIR reflectance, similar to the effects observed for woody stems in trees and shrubs [11], [13]. However, small increases in standing litter cause more than a proportional increase in canopy reflectance because of its impact on nonlinear mixing, especially in NIR and SWIR regions [11]. Fig. 8 shows residual trends for chaparral canopies, serpentine and greenstone grasses. The RMSE by wavelength is similar for chaparral and grasses but the magnitude is greater in grasses, 

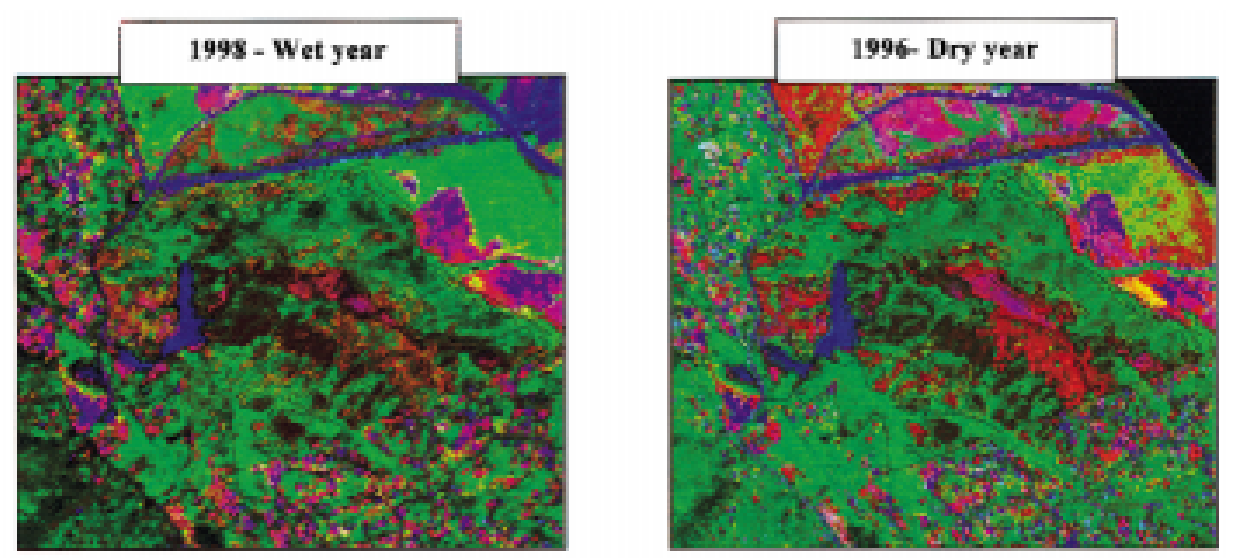

Fig. 5. Unmixing results using three endmembers: soil (red), green vegetation (green), and shade (blue) in spring at Jasper Ridge. Areas with higher proportion of red correspond to the grasslands.
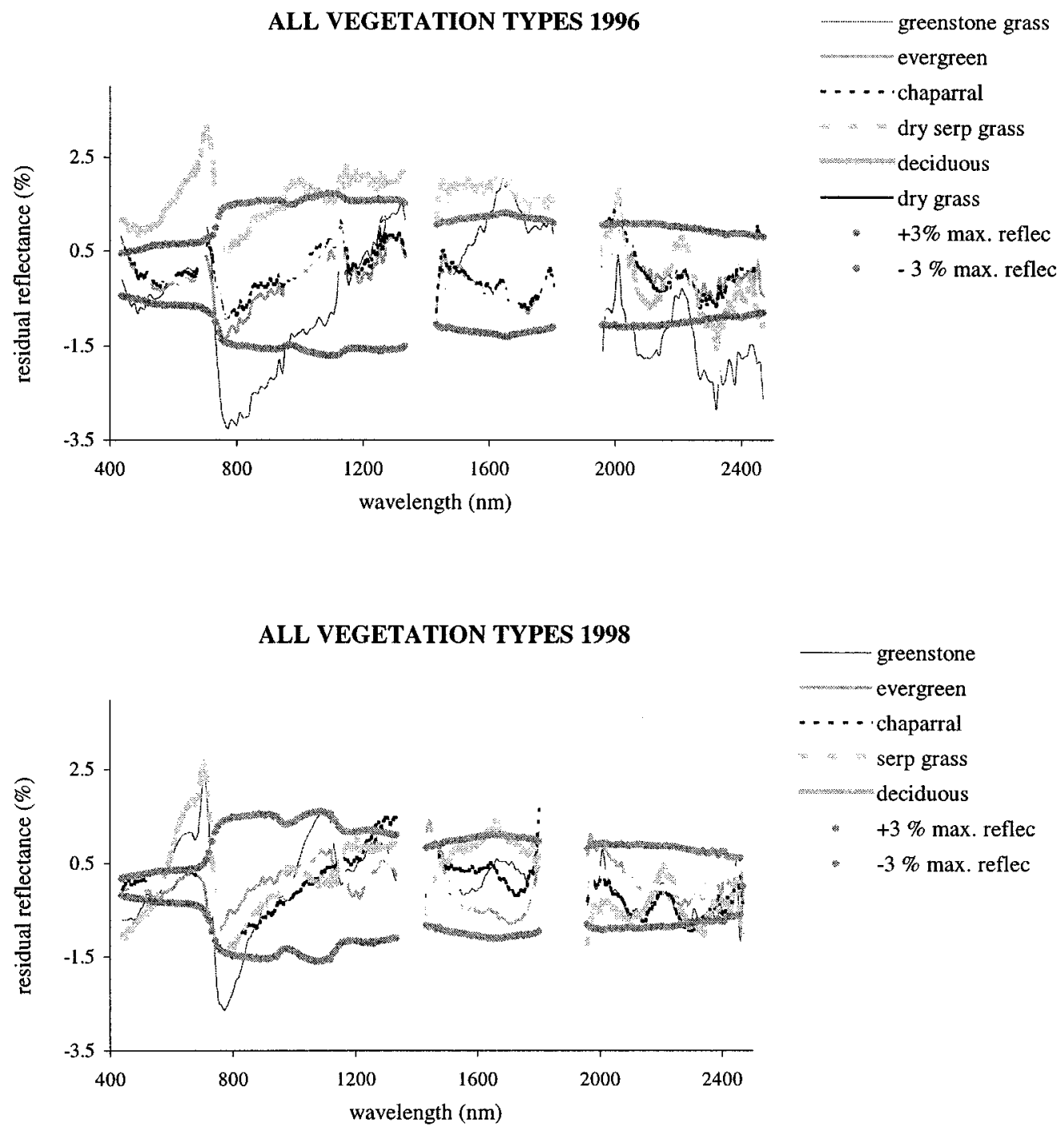

Fig. 6. Comparison of residuals across spectral bands between observed AVIRIS reflectance and modeled with unmixing in 1996 and 1998 for different vegetation types. Grasses present higher residuals as a consequence of senescence.

despite similar cover fractions. Also, serpentine grasses show a red-edge shift with respect to greenstone grasses due to lesser chlorophyll absorption, since they are more senescent than greenstone grasses. 

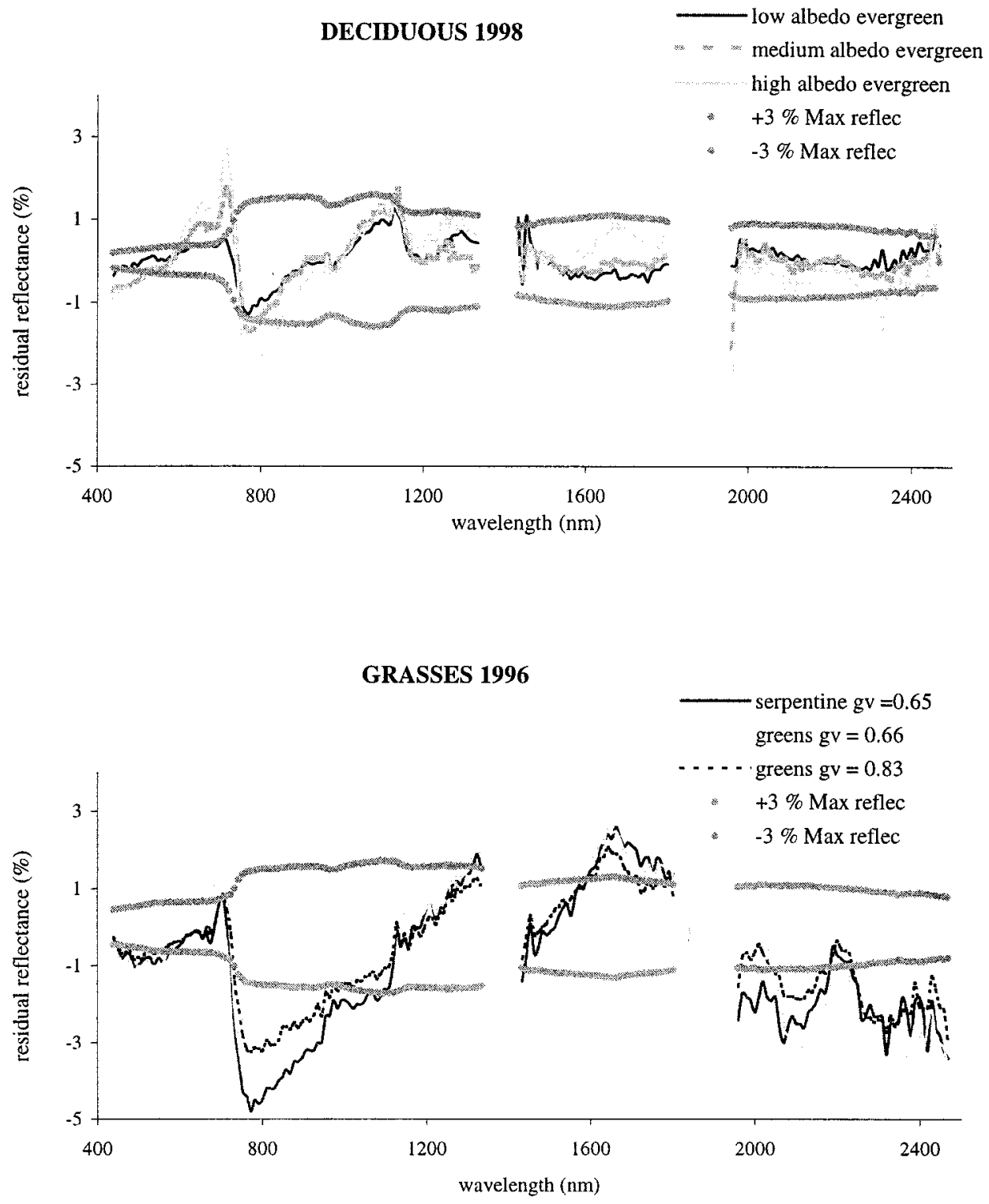

Fig. 7. Residuals between observed and predicted reflectance suggesting nonlinear scattering effects due to increasing canopy levels in high transmitting foliage and background effects from soil and litter in the grasses.

\section{Unmixing with Four Endmembers in Grassland Areas}

Nonlinear mixing effects can lead to overestimation of green vegetation fractions making change detection unreliable. To minimize this problem, based on the error analysis above, an additional endmember was added to pixels in the grasslands to account for the unexplained reflectance. The fourth endmember was a senescing but not totally dry greenstone grass, based on its PPI ranking (Fig. 4). Unmixed fractions in the grasslands were consistent with expected values at the late April phenological stage. RMSE decreased to the magnitude of the mean RMSE for the three endmember model used in the other vegetation types. Trials using a dry litter endmember, without any red edge, yielded negative and unrealistic fractions with high RMSE.

In conclusion, the final SMA results consisted of soil, evergreen vegetation, and shade fractions for all of JRBP except for serpentine and greenstone grasslands where an additional senes- cent grass endmember was included. Grassland boundaries were delimited using the JRBP vegetation map. Soil, litter, and vegetation fractions were rescaled to sum to $100 \%$ after removing the shade fraction. It was assumed that shade fractions were equally distributed between soil and vegetation components. However, if shade fractions are contributed by shadows in addition to photometric shade, subpixel topography could affect landscape materials differently and cause rescaled fractions to be inaccurate [2]. Comparison of shade fractions against a DEM did not reveal a vegetation dependent residual shade.

\section{Differences in Mean Unmixed Fractions}

Mean fractions of green vegetation $(\mathrm{GV})$, soil, and plant litter/dry grass (i.e., nonphotosynthetic vegetation or NPV) were calculated for both years for each vegetation polygon (Fig. 9). Chaparral, deciduous forest, and evergreen forest show less plasticity in growth response to rainfall. Comparison of wet and dry years shows that herbaceous annuals are most 

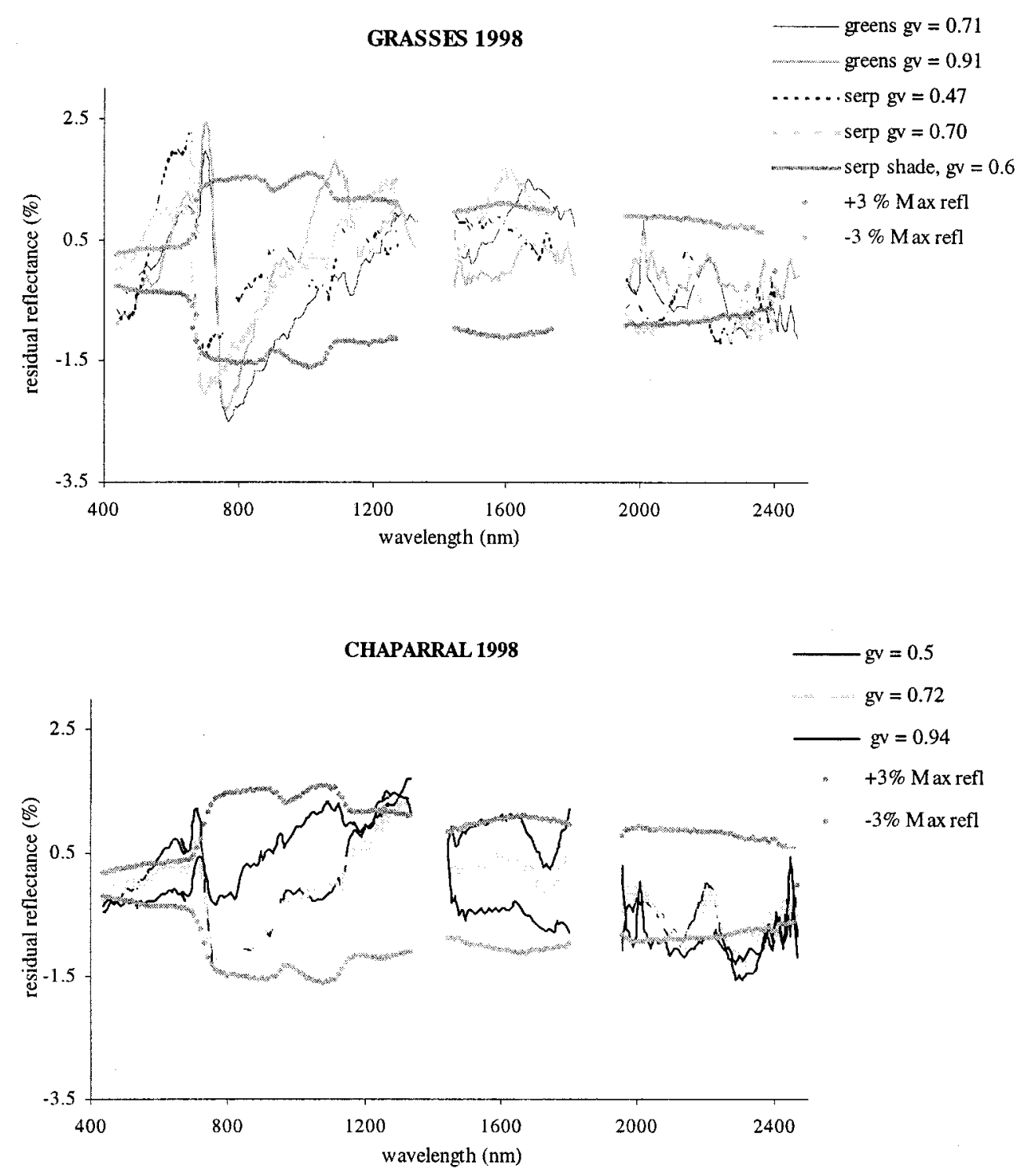

Fig. 8. Differences in residuals between grasslands and chaparral areas showing nonmodeled reflectance from dry grass and litter at the red-edge and in the SWIR regions.

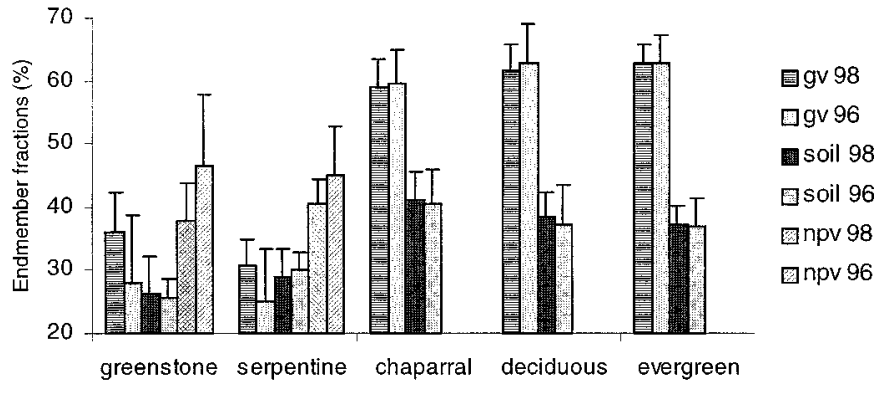

Fig. 9. Differences between mean unmixing fractions in 1996 and 1998 calculated for each vegetation community. Error bars represent one standard deviation for the fraction distribution within each vegetation polygon and year.

affected by the increased rainfall in the wet year. Dry grass fractions were lower in the wet year than in the dry year. However, the sum of green and dry vegetation fractions in both years remained constant. This could indicate that changes in community composition between dry and wet years is greater than effects on primary productivity. Landscape scale phenological changes in grasslands arise mainly through changes in species composition [36]. Differences in structure and canopy geometry among vegetation types can produce different green vegetation fractions for the same biomass, limiting the value of comparisons between vegetation types [14]. In any case, the high spatial variability of fractions within a year makes mean differences insignificant as is shown in Fig. 9.

\section{E. Change Detection Using Unmixed Fractions}

The percentage change between 1996 and 1998 was calculated for normalized fractions for all vegetation types. To evaluate significant changes in unmixed fractions, a threshold of one standard deviation was set. Mapped significant changes between years are shown in Fig. 10. Increases mean higher fractions occurred in 1996 compared to 1998. In general, significant changes in plant communities (other than grasslands) are from either increases in green vegetation fractions and corresponding 

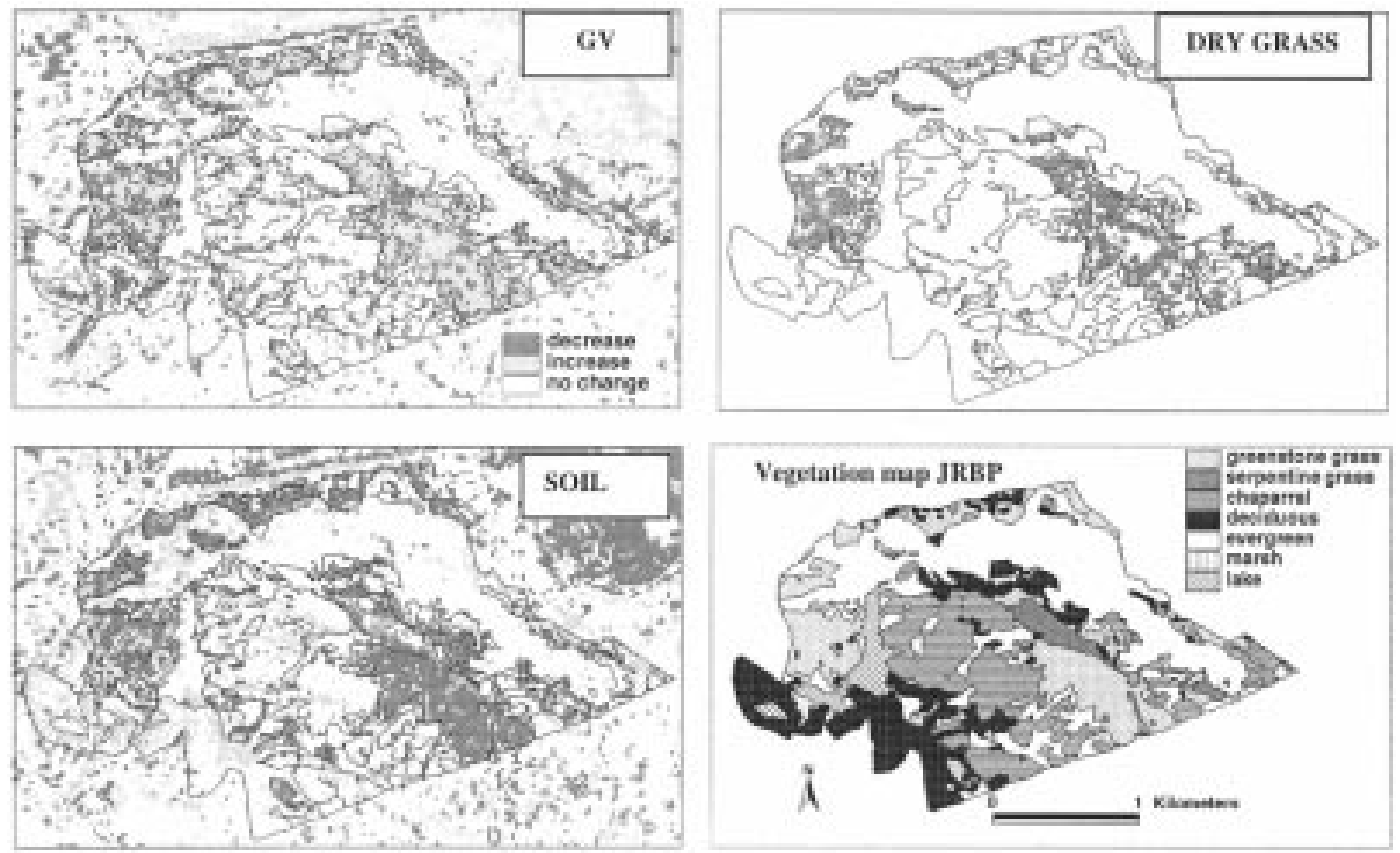

Fig. 10. Significant changes in green vegetation (GV), dry grass, and soil fractions between 1996 and 1998. Black areas correspond to decreases and gray areas to increases in the wet year (1998) relative to the dry year (1996).

decreases in soil fractions or vice versa. Evergreen forest communities did not show any change between years. In some areas of the deciduous forest, green vegetation fractions decreased and soil fractions increased in the wet year. One explanation for this contra-intuitive result might be due to delays in the phenological cycle of this vegetation type, leading to later peaks in biomass [36]. Chaparral vegetation shows the greatest interannual change after the grasslands, and shows both increases and decreases in different pixels. This irregular pattern may be a response to variable grass abundance within the mapped chaparral areas.

Grasslands show the most significant changes in green vegetation and soil fractions between years. The patterns are complex and spatial trends are not always correlated. Thus, in the wet year, green vegetation fractions increase in most pixels but decreases in other pixels are common. Soil fractions mainly decreased between 1996 and 1998. However, in the wet year, dry grass fractions never increased but either decreased or remain unchanged. When NPV fractions decreased, soil fractions, in general, tend to decrease too and green vegetation fractions showed a corresponding increase.

\section{CONCLUSIONS}

Linear SMA of AVIRIS data is appropriate to capture some of the complexity of ecosystem interrelations and landscape spatial heterogeneity in a semiarid grassland. Subtle changes in vegetation structure between dry and wet years can be detected. Because pixel heterogeneity within vegetation types is high, mean differences between years for a vegetation type are not significantly different. However on a pixel basis, significant differences in fractional abundances are detected between coregistered images.
From among these vegetation communities, grasslands are the most plastic in their response to climatic variability, and spectral changes might be responding to changes in grassland structure as well as abundance. LAI and growth plasticity in evergreen and deciduous forests are less responsive than grasslands to differences in interannual rainfall as they have access to water layers at deeper soil depths. In chaparral communities, most changes are explained by annual grasses growing within the shrub communities.

Improvements in the performance of the AVIRIS instrument only partially explain the better fitness of the SMA model in 1998 with respect to 1996. Nonlinear scattering due to senescing vegetation and high green cover of highly transmitting foliage also affected the results. Including an additional endmember in the grasslands improved the fit of the SMA model. The results from the change detection analysis of vegetation at JRBP demonstrate the importance of performing site-specific and community-specific analyses to characterize vegetation structure. Although linear SMA provides relatively good characterization of the general landscape conditions, the model is not flexible enough to accommodate the range of natural vegetation variability throughout the landscape. To fully characterize ecosystem structure, it is necessary to account for changes in bidirectional reflectance (BDRF) in the subpixel components since multiple scattering overestimates the results from a linear scattering model. Addressing this research direction will require the use of radiative transfer models that are based on parameterizing leaf optical properties, and vegetation structure and are used to invert hyperspectral images. In addition, an increase in the temporal coverage of hyperspectral data is needed to track phenological events in different vegetation communities and will provide better understanding of vegetation dynamics. 


\section{ACKNOWLEDGMENT}

The authors thank K. Keightley for his help in preprocessing the AVIRIS images and G. Scheer for computer support. We especially thank Dr. P. Zarco-Tejada for his review and advice on the manuscript.

\section{REFERENCES}

[1] J. W. Bartolome, "Local temporal and spatial structure," in Grassland Structure and Function. California Annual Grassland, L. F. Huenneke and H. A. Mooney, Eds. New York: Kluwer, 1989, pp. 47-56.

[2] M. O. Smith, S. L. Ustin, J. B. Adams, and A. R. Gillespie, "Vegetation in deserts: I. A regional measure of abundance from multispectral images," Remote Sens. Environ., vol. 31, pp. 1-26, Jan. 1990.

[3] C. B. Field, F. S. Chapin, P. A. Matson, and H. A. Mooney, "Responses of terrestrial ecosystems to the changing atmosphere: A resource-based approach," Annu. Rev. Ecol. Syst., vol. 23, pp. 201-235, 1992.

[4] A. J. Bloom, F. S. Chapin III, and H. A. Mooney, "Resource limitation in plants: an economic analogy," Annu. Rev. Ecol. Syst., vol. 16, pp. 363-92, 1985 .

[5] E. F. Lambin, "Change detection at multiple temporal scales: seasonal and annual variations in landscape variables," Photogram. Eng. Rem. Sens., vol. 62, pp. 931-938, August 1996.

[6] R. J. Hobbs, "Remote sensing of spatial and temporal dynamics of vegetation," in Remote Sensing of Biosphere Functioning, R. J. Hobbs and H. A. Mooney, Eds. New York: Springer-Verlag, 1990, pp. 203-220.

[7] S. A. Levin, "Concepts of scale at the local level," in Scaling Physiological Processes Leaf to Globe, J. R. Ehleringer and C. B. Field, Eds. New York: Academic, 1993, pp. 7-18.

[8] P. C. Miller, D. K. Poole, and P. M. Miller, "The influence of annual precipitation, topography, and vegetative cover on soil moisture and summer drought in Southern California," Oecologia, vol. 56, pp. 385-391, 1983.

[9] H. A. Mooney, D. J. Parsons, and J. Kummerow, "Plant development in Mediterranean climates," Ecol. Stud. Anal. Synth., vol. 8, pp. 255-267, 1974.

[10] J. A. Young and R. A. Evans, "Seed production and germination dynamics in California annual grasslands," in Grassland Structure and Function. California Annual Grassland, L. F. Huenneke and H. A. Mooney, Eds. New York: Kluwer, 1989, pp. 47-56.

[11] G. P. Asner, "Biophysical and biochemical sources of variability in canopy reflectance," Remote Sens. Environ., vol. 64, pp. 234-253, June 1998.

[12] A. R. Huete, "Suitability of spectral indices for evaluating vegetation characteristics on arid rangelands," Remote Sens. Environ., vol. 23, pp. 213-232, June 1987.

[13] J. Otterman, T. Brakke, and J. Smith, "Effects of leaf transmittance versus leaf-reflectance on bidirectional scattering from canopy/soil surface: an analytical study," Remote Sens. Environ., vol. 54, pp. 49-60, Oct. 1995.

[14] J. A. Gamon, C. B. Field, D. A. Roberts, S. L. Ustin, and R. Valentini, "Functional patterns in an annual grassland during and AVIRIS overflight," Remote Sens. Environ., vol. 44, pp. 239-253, May-June 1993.

[15] S. L. Ustin, C. A. Wessman, B. Curtiss, E. Kasischke, J. Way, and V. C. Vanderbilt, "Opportunities for using the EOS imaging spectrometers and synthetic aperture radar in ecological models," Ecology, vol. 72, pp. 1934-1945, Dec. 1991

[16] J. M. Paruelo and W. K. Lauenroth, "Regional patterns of normalized difference vegetation index in North American shrublands and grasslands," Ecology, vol. 76, pp. 1888-1898, Sept. 1995.

[17] C. J. Tucker, "Use of Near Infrared/Red radiance ratios for estimating vegetation biomass and physiological status," in Proc. 11th Int. Symp. Remote Sensing of Environment, vol. 1, Ann Arbor, MI, Apr. 1977, pp. 493-494.

[18] C. M. Malstrom, M. V. Thomspson, G. P. Juday, S. O. Los, J. T. Randerson, and C. F. Field, "Interannual variation in global-scale net primary production: Testing model estimates," Global Biogeochem. Cycles, vol. 11, pp. 367-392, Sept. 1997.

[19] D. S. Schimel and B. H. Brashwell, "Continental scale variability in ecosystem processes: models, data, and the role of disturbance," Ecol. Monogr., vol. 67, pp. 251-271, May 1997.

[20] R. O. Green, M. L. Eastwood, C. M. Sarture, T. G. Chrien, M. Aronsson, B. J. Chippendale, J. A. Faust, B. E. Pavri, C. J. Chovit, M. S. Solis, M. R. Olah, and O. Williams, "Imaging spectroscopy and the Airborne Visible Infrared Imaging Spectrometer (AVIRIS)," Remote Sens. Environ., vol. 65, pp. 227-248, Sept. 1998.
[21] D. A. Roberts, G. T. Batista, J. L. G. Pereira, E. K. Waller, and B W. Nelson, "Change identification using multitemporal spectra mixture analysis: Applications in eastern Amazonia," in Remote Sensing Change Detection: Environmental Monitoring Applications and Methods, R. S. Lunetta and C. D. Elvidge, Eds. Ann Arbor, MI: Ann Arbor Press, 1998, pp. 137-158.

[22] S. L. Ustin, D. A. Roberts, and Q. J. Hart, "Seasonal vegetation patterns in a California coastal savanna derived from Advanced Visible/Infrared Imaging Spectrometer (AVIRIS) data," in Remote Sensing Change Detection: Environmental Monitoring Applications and Methods, C. D. Elvidge and R. Lunetta, Eds. Ann Arbor, MI: Ann Arbor Press, 1998, ch. 10, pp. 163-176.

[23] R. O. Green, B. Pavri, J. Faust, and O. Williams, "AVIRIS radiometric laboratory calibration, inflight validation and a focused sensitivity analysis in 1998," in Summaries of the Eight JPL Airborne Earth Science Workshop. Pasadena, CA, 1999, pp. 161-175.

[24] R. S. Lunetta, "Applications, project formulation, and analytical approach," in Remote Sensing Change Detection: Environmental Monitoring Applications and Methods, C. D. Elvidge and R. Lunetta, Eds. Ann Arbor, MI: Ann Arbor Press, 1998, pp. 1-14.

[25] D. Yuan, C. D. Elvidge, and R. S. Lunetta, "Survey of multispectral methods for land cover change analysis," in Remote Sensing Change Detection: Environmental Monitoring Methods and Applications, C. D. Elvidge and R. Lunetta, Eds. Ann Arbor, MI: Ann Arbor Press, 1998, pp. 21-35.

[26] K. McGwire, T. Minor, and L. Fenstermaker, "Hyperspectral mixture modeling for quantifying sparse vegetation cover in arid environments," Remote Sens. Environ., vol. 72, pp. 360-374, June 2000.

[27] S. L. Ustin, M. O. Smith, and J. B. Adams, "Remote sensing of ecological processes: A strategy for developing and testing ecological models using spectral mixture analysis," in Scaling Physiological Processes: Leaf to Globe, J. R. Ehleringer and C. Field, Eds. New York: Academic, 1993, pp. 339-357.

[28] J. E. Elmore, J. F. Mustard, S. J. Manning, and D. B. Lobell, "Quantifying vegetation change in semi-arid environments: precision and accuracy of spectral mixture analysis and the normalized difference vegetation index," Remote Sens. Environ., vol. 73, pp. 87-102, July 2000.

[29] N. S. Lucas, P. J. Curran, S. E. Plummer, and F. M. Danson, "Estimating the stem carbon production of a coniferous forest using an ecosystem simulation model driven by the remotely sensed red edge," Int. J. Remote Sens., vol. 21, pp. 619-631, Mar..

[30] M. O. Smith, S. L. Ustin, J. B. Adams, and A. R. Gillespie, "Vegetation in deserts: II. Environmental influences on regional abundance," Remote Sens. Environ., vol. 31, pp. 27-52, Jan. 1990b.

[31] D. L. S. Chong, E. Mougin, and J. P. Gastelluet-Chegorry, "Relating the global vegetation index to net primary productivity and actual evapotranspiration over Africa," Int. J. Remote Sens., vol. 14, pp. 1517-1546, May 1993.

[32] P. P. Tans, I. Y. Fung, and T. Takahasi, "Observational constraints on the atmospheric $\mathrm{CO}_{2}$ budget," Science, vol. 247, no. 4949, pp. 1431-1438, Mar. 1990.

[33] J. K. Vanclay and R. A. Preston, "Utility of Landsat Thematic Mapper data for mapping site productivity in tropical moist forests," Photogram. Eng. Remote Sens., vol. 56, pp. 1383-1388, Oct. 1990.

[34] J. W. Boardman, F. A. Kruse, and R. O. Green, "Mapping target signatures via partial unmixing of AVIRIS data," in Summaries of the Fifth JPL Airborne Earth Science Workshop, vol. 1. Pasadena, CA, 1995, pp. 23-26.

[35] J. B. Adams, M. O. Smith, and P. E. Johnson, "Spectral mixture modeling: A new analysis of rock and soil types at the Viking Lander 1 site," J. Geophys. Res., vol. 91, pp. 8098-8112, 1986.

[36] J. A. Gamon, C. B. Field, M. L. Goulden, K. L. Griffen, A. E. Hartley, G. Joel, J. Peñuelas, and R. Valentini, "Relationships between NDVI, canopy structure, and photosynthesis in three California vegetation types," Ecol. Appl., vol. 5, pp. 28-41, Feb. 1995.

[37] N. R. Chiarello, "Phenology of California grasslands," in Grassland Structure and Function. California Annual Grassland, L. F. Huenneke and H. A. Mooney, Eds. New York: Kluwer, 1989, pp. 47-56.

[38] B. M. Pavlik, P. C. Muick, S. Johnson, and M. Popper, Oaks of California. Los Olivos, CA: Cachuma Press and The California Oak Foundation, 1991, p. 184.

[39] R. O. Green, J. E. Conel, J. S. Margolis, C. J. Bruegge, and G. L. Hoover, "An inversion algorithm for retrieval of atmospheric and leaf water absorption from AVIRIS radiance with compensation for atmospheric scattering," in Proc. 2nd Annu. JPL Airborne Visible/Infrared Imaging Spectrometer Workshop, R. O. Green, Ed., Pasadena, CA, 1991, JPL 91-28, pp. 51-61. 
[40] S. L. Ustin, Q. J. Hart, L. Duan, and G. Scheer, "Vegetation mapping on hardwood rangelands in California," Int. J. Remote Sensing, vol. 17, pp. 3015-3036, 1996.

[41] S. L. Ustin, M. O. Smith, S. Jacquemoud, M. M. Verstraete, and Y. Govaerts, "Geobotany: vegetation mapping for Earth sciences," in Remote Sensing for the Earth Sciences, Manual of Remote Sensing, 3 ed, A. Rencz, Ed. New York: Wiley, 1999, vol. 3, pp. 189-248.

[42] D. A. Roberts, M. O. Smith, and J. B. Adams, "Green vegetation, nonphotosynthetic vegetation, and soils in AVIRIS data," Remote Sens. Environ., vol. 44, pp. 255-269, May-June 1993.

[43] M. O. Smith, S. L. Ustin, J. B. Adams, and A. R. Gillespie, "Vegetation in deserts II. Environmental influences on regional abundance," Remote Sens. Environ., vol. 29, pp. 27-52, 1990b.

[44] S. L. Ustin, J. B. Adams, C. D. Elvidge, M. Rejmanek, B. N. Rock, M. O. Smith, R. W. Thomas, and R. A. Woodward, "Thematic mapper studies of semiarid shrub communities," BioScience, vol. 36, no. 7, pp. 446-452, 1986.

[45] J. W. Boardman, "Automating spectral unmixing of AVIRIS data using convex geometry concepts," in Summaries 4th Annu. JPL Airborne Geoscience Workshop, vol. 1, Pasadena, CA, 1993, JPL Pub. 93-26, pp. $11-14$.

[46] S. L. Ustin and Q.-F. Xiao, "Mapping of forested ecosystems in interior central Alaska," Int. J. Remote Sens.

[47] J. W. Boardman, "Post-ATREM polishing of AVIRIS apparent reflectance data using EFFORT: a lesson in accuracy versus precision," in Summaries 7th JPL Airborne Earth Science Workshop, vol. 1, Pasadena, CA, 1998, JPL Pub. 97-21, p. 21.
Monica Garcia received the B.S. degree in agricultural engineering and argonomy from the Polytechnique University of Madrid, Madrid, Spain, in 1996, and the M.S. degree from the University of California, Davis, in 1998, specializing in the use of GIS and remote sensing in natural resources management. She is currently pursuing the Ph.D. degree at the Polytechnique University of Madrid.

She was with the Department of Rural Engineering, Polytechnique University of Madrid, working on spectroscopy applications in agriculture and food quality, until Fall 1997. Her research interests are in hyperspectral remote sensing to study land use change and vegetation climate relationships.

Susan L. Ustin (M'90) received the B.S. degree in biology from California State University, Hayward, in 1974, and the Ph.D. degree in botany from the University of California, Davis, in 1983. Her dissertation research involved the physiological ecology of halophytic plants.

She began working on imaging spectrometery data as a Postdoctoral Fellow at the beginning of the Airborne Imaging Spectrometery Program. Her current interests are in uses of hyperspectral data for detection of ecological processes. She joined the Faculty, University of California, Davis, in 1991, and is currently Professor of resource science and Director of the Center for Spatial Technologies and Remote Sensing. 